\title{
Pemberdayan Keterampilan Mitigasi Bencana Berbasis Project Based Learning
}

\author{
${ }^{1}$ Henita Rahmayanti, ${ }^{2}$ Ilmi Zajuli Ichsan, ${ }^{3}$ Endah Sri Wahyuni, \\ ${ }^{4}$ Ana Amalia Islami, ${ }^{5}$ Rosi Utari, ${ }^{6}$ Elit Nurul Kholifah
}

\author{
${ }^{1,3,4}$ Universitas Negeri Jakarta, Jl. Rawamangun Muka, Jakarta Timur, DKI Jakarta, Indonesia \\ 2,5,6 Universitas Mohammad Husni Thamrin, Jakarta Timur, DKI Jakarta, Indonesia \\ email:'henita.rahmayanti@unj.ac.id; ${ }^{2}$ ilmizajuli95@outlook.com; ${ }^{3}$ endahdara630@gmail.com; \\ 4anaamaliaislami3@gmail.com; rosiutari07@gmail.com; ${ }^{6}$ elitnurulkholifah05@gmail.com
}

\begin{abstract}
Flooding is a problem that often occurs in urban areas. The flood disaster that occurred in early 2020 left various negative impacts on the environment. This causes flooding to become a problem that must be solved. The purpose of this activity is to empower flood mitigation skills in the community through environmental seminars. The method of activities carried out is by lectures and discussions in seminars. Data collection using the instruments used are test questions and questionnaires related to flood mitigation. Analysis of the data used is to compare the average results between before and after the activity. The results of this activity indicate that the knowledge score has increased from before (28.45) to be higher after the activity (34.93), as well as related to previous flood mitigation behavior (66.62) and has increased after (70.52). In addition, seminar participants are required to create a project. This indicates that this Project Based Learning (PjBL)-based environmental seminar has become an educational innovation
\end{abstract}

Keywords: Flood, mitigation, seminar.

Abstrak. Banjir merupakan sebuah masalah yang sering terjadi di wilayah perkotaan. Bencana banjir yang terjadi pada awal tahun 2020 menyisakan berbagai dampak negatif bagi lingkungan. Hal ini menyebabkan banjir menjadi sebuah masalah yang harus diselesaikan. Tujuan dari kegiatan ini adalah untukmemberdayakan keterampilan mitigasi banjir pada masyarakat melalui seminar lingkungan. Metode kegiatan yang dilaksanakan adalah dengan ceramah dan diskusi dalam seminar. Pengumpulan data menggunakan instrumen yang digunakan adalah soal tes dan kuesioner terkait dengan mitigasi banjir. Analisis data yang digunakan adalah dengan membandingkan hasil rata-rata antara sebelum dan sesudah kegiatan. Hasil dari kegiatan ini menunjukkan bahwa skor pengetahuan mengalami peningkatan dari sebelum (28.45) menjadi lebih tinggi sesudah kegiatan (34.93), begitu juga terkait dengan perilaku mitigasi banjir sebelumnya (66.62) dan mengalami peningkatan sesudahnya (70.52). Selain itu, peserta seminar diharuskan membuat sebuah proyek. Hal ini menandakan bahwa kegiatan seminar lingkungan berbasis Project Based Learning (PjBL) ini menjadi sebuah inovasi pendidikan.

Kata Kunci: Banjir, mitigasi, seminar.

\section{Pendahuluan}

Awal tahun 2021, ibu kota kembali dirundung duka, yaitu kembali terjadi banjir. Saat ini pun masyarakat masih mengalami masa sulit karena pandemik Coronavirus Disease 2019 (COVID-19) kemudian makin diperburuk dengan naiknya jumlah kasus COVID-19. Oleh karena itu, harus dilakukan upaya dalam mengedukasi masyarakat terkait dengan mitigasi banjir. Upaya edukasi ini sudah dilakukan dengan banyak cara mulai dari membuat media pembelajaran hingga 
melaksanakan berbagai program ramah lingkungan (Buzov, 2014; Gampell et al., 2017; Kanchanabhandhu \& Woraphong, 2016; Muthukrishnan \& Kelley, 2017). Upaya tersebut harus dilaksanakan secara konsisten agar bisa memperoleh hasil yang diharapkan.

Masyarakat yang teredukasi dengan baik semaksimal mungkin akan menghindari berbagai hal yang membuat lingkungan tercemar. Keterampilan mitigasi menjadi sebuah komponen penting untuk menghadapi berbagai situasi bencana, terutama untuk mengatasi banjir yang seringkali terjadi setiap tahunnya. Hal ini mendorong upaya edukasi yang inovatif di tengah masa pandemik COVID-19 menjadi urgen untuk dilakukan. Upaya edukasi ini juga bisa dilakukan dengan bantuan berbagai platform pendukung, yaitu dengan aplikasi teleconference. Aplikasi ini sangat membantu dalam pelaksanaan seminar dan pembelajaran dari jarak jauh (Ng, 2018; Sparrow et al., 2020; Xia, 2017).

Banjir yang terjadi pada masa pandemi tentunya akan menyulitkan bagi berbagai lapisan masyarakat. Hal itu akan menyebabkan berbagai aktivitas ekonomi menjadi terganggu akibat adanya pandemik ini. Selain itu, upaya untuk mencegah terjadinya banjir juga menjadi lebih sulit karena masyarakat tidak bisa turun langsung ke lapangan, melainkan harus menggunakan protokol kesehatan yang ketat. Tentunya hal ini akan menyulitkan gerak dari masyarakat itu sendiri dan instansi yang terkait dengan bencana banjir ini. Oleh karena itu, perlu dilakukan berbagai upaya alternatif untuk mengatasi masalah ini agar tidak berlanjut lebih parah.

Banjir sendiri merupakan bencana yang sering terjadi di wilayah perkotaan di Indonesia. Bencana ini biasanya melanda berbagai wilayah dengan kondisi drainase yang buruk dan tidak sesuai dengan ketentuan. Banjir biasanya terjadi karena adanya peningkatan curah hujan yang drastis sehingga volume air meluap dan menggenangi berbagai wilayah di perkotaan. Akibat yang ditimbulkan dari banjir itu adalah sulitnya menjalankan berbagai upaya terkait dengan pencegahan banjir. Jadi, bencana itu sulit untuk dicegah di masa pandemik ini. Banjir seringkali terjadi di wilayah perkotaan dengan dampak yang parah bagi ekonomi masyarakat mereka. Banjir ini biasanya menjadi masalah rumit dalam kehidupan masyarakat di perkotaan jika dibandingkan dengan masyarakat yang tinggal di desa. Dampak dari banjir ini yang lebih parah dirasakan oleh warga yang tinggal di wilayah tepi sungai, termasuk dirasakan oleh siswa SMK. Dalam hal ini siswa SMK perlu berperan dalam menerapkan berbagai keilmuwannya dalam mencegah banjir.

Kegiatan yang bisa dilakukan dalam rangka edukasi terkait dengan pencegahan dan upaya penanggulangan banjir adalah dengan membuat sebuah seminar. Kegiatan ini dapat membuat masyarakat ikut berpartisipasi untuk mengkaji lebih jauh terkait dengan berbagai faktor penyebab banjir. Selain itu, kegiatan seminar ini bisa digabungkan dengan kegiatan berbasis project atau dikenal dengan Project Based Learning (PjBL). Kegiatan yang diintegrasikan dengan pembuatan project akan lebih implementatif bagi masyarakat. Hal ini menjadikan upaya edukasi dengan berbasis project ini menjadi penting untuk dilakukan.

PjBL sendiri adalah sebuah model pembelajaran yang mengutamakan pada hasil dari pembelajaran berupa produk. PjBL dianggap sesuai dengan keperluan untuk mengatasi masalah lingkungan yang lebih lanjut. Hasil dari kegiatan PjBL ini diharapkan dapat bermanfaat produknya bagi masyarakat itu sendiri agar bisa dipakai dalam kehidupan sehari-hari (Al-Balushi \& Al-Aamri, 2014; Talmi et al., 2018).

ProdukPjBLyangbisadibuatadalah berupa poster, hasil daur ulang sampah, 
dan barang yang merupakan olahan dari limbah. PjBL sebagai sebuah model pembelajaran diharapkan dapat dipakai oleh masyarakat luas untuk keperluan sehari hari. Siswa SMK memiliki kesesuaian dengan bidang mitigasi bencana banjir. Hal ini disebabkan mereka harus mengimplementasikan berbagai ilmu yang dimiliki.

Siswa Sekolah Menengah Kejuruan (SMK) dalam hal ini menjadi pihak yang penting untuk bisa turut serta dalam sebuah upaya mitigasi banjir. Hal ini disebabkan siswa merupakan generasi muda yang juga memiliki peran dalam kehidupan bermasyarakat. Oleh karena itu, siswa SMK selain bisa bekerja di tempat yang dituju juga bisa bermanfaat bagi lingkungan hidup di sekitarnya. Tujuan dari kegiatan ini adalah untuk memberdayakan keterampilan mitigasi banjir pada masyarakat. Dalam hal ini, masyarakat yang dimaksud adalah siswa SMK.

\section{Metode Ilmiah}

Kegiatan pengabdian ini menggunakan metode ceramah dan diskusi melalui rangkaian kegiatan seminar mitigasi banjir. Seminar dilaksanakan secara online (daring) karena masih belum memungkinkannya dilakukan seminar secara langsung karena adanya pandemik COVID-19. Adapun pelaksanaan dari kegiatan ini dilaksanakan pada tahun 2021. Peserta kegiatan ini adalah siswa SMK di Jakarta yang tinggal di daerah yang pernah terendam banjir. Perubahan keterampilan mitigasi banjir menjadi parameter yang diukur dalam kegiatan ini. Ada dua aspek, yaitu pada aspek pengetahuan dan perilaku mitigasi banjir. Setelah peserta menjawab soal yang diberikan setelah pelaksanaan seminar, peserta diminta untuk membuat sebuah karya sebagai bentuk implementasi project based learning ( $\mathrm{PjBL})$.

\section{Hasil dan Pembahasan}

Masa pandemik COVID-19 saat ini tidak menjadi kendala untuk memberikan pengetahuan terkait mitigasi banjirkepada masyarakat terutama siswa. Justru, hal tersebut malah menjadikan momen ini sebagai pengembangan kreativitas, salah satunya adalah melaksanakan kegiatan seminar secara daring atau biasa disebut webinar. Kegiatan itu dilaksanakan dengan menggunakan aplikasi google meet. Penggunaan google meet tidak memiliki batasan waktu dan dapat digunakan secara gratis sehingga dapat dilaksanakan secara efektif. Aplikasi ini juga tidak memiliki batasan jumlah partisipan sehingga dapat menampung puluhan partisipan bahkan ratusan. Selama acara berlangsung peserta sangat aktif dalam melakukan diskusi. Meskipun kegiatan berjalan dengan lancar terdapat beberapa kendala, yaitu beberapa siswa memiliki kendala jaringan sehingga terkadang pada saat webinar berlangsung beberapa siswa keluar masuk aplikasi. Adapun dokumentasi dari kegiatan dapat dilihat pada gambar 1 .

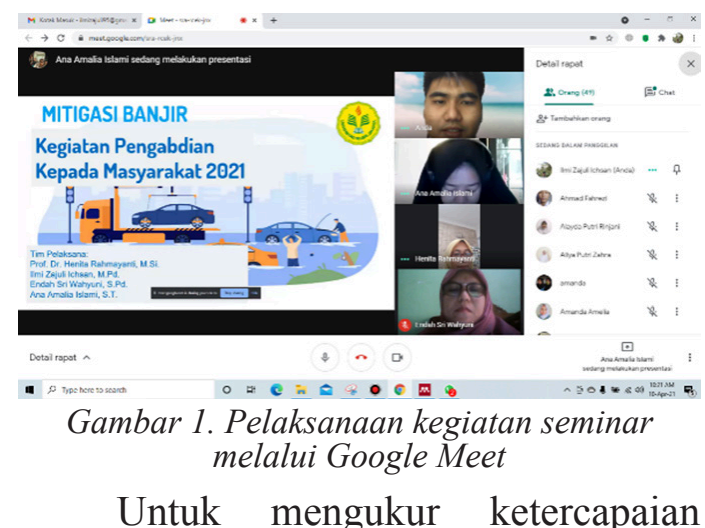
hasil seminar, selain dengan pre-test dan post-test, siswa diminta untuk membuat karya kreatif (project) yang dapat digunakan untuk menyampaikan pengetahuan terkait mitigasi bencana banjir. Proyek ini dikerjakan oleh siswa secara berkelompok yang terdiri dari tiga siswa,. Dalam pembuatan proyek ini siswa diminta memilih salah satu proyek yang mereka sukai dan mereka pahami 
cara pembuatanya. Dengan demikian, siswa dituntut untuk berkolaborasi dengan teman dan juga berpikir kreatif dalam menuangkan ide gagasan (Knowlton \& Sharp, 2015; Yusnaeni et al., 2017). Proyek yang dibuat oleh siswa di antaranya adalah poster. Poster merupakan salah satu media yang dipakai untuk menyampaikan pesan kepada masyarakat dengan mudah. Poster ini berisi gambar dengan warna yang menarik dan tulisan yang mengandung pesan layanan masyarakat, dalam hal ini mengenai mitigasi banjir. Proyek yang kedua adalah komik. Komik tidak jauh berbeda dengan poster. Dalam komik juga terkandung gambar dan tulisan yang isinya adalah pengetahuan tentang mitigasi banjir. Hanya saja komik dibuat dalam bentuk alur cerita. Proyek yang ketiga adalah video yang berbeda dengan poster dan komik. Jika poster dan komik hanya berupa gambar dan tulisan, video mempunyai perbedaan, yaitu gambar bergerak dan mempunyai suara. Dengan metode ini diharapkan siswa mampu mengidentifikasi mitigasi banjir melalui karya kreatif yang sesuai dengan kemampuan dan bakat siswa. Selain itu, mereka diharapkan dapat menyampaikan pesan kepada masyarakat umum mengenai mitigasi banjir dengan mudah.

Berdasarkan hasil skor Pre-Test dan Post-tes, pengetahuan siswa terkait mitigasi banjir terlihat bahwa pada indikator enam mendapatkan kenaikan skor yang paling tinggi. Hal tersebut terjadi karena pada masa sekarang siswa sudah mahir dalam penggunaan media sosial. Dengan begitu, jika siswa akan mengampanyekan mitigasi banjir, tentunya banyak ide inovatif yang bisa dikembangkan, seperti membuat poster, komik, video animasi, dan masih banyak lagi.

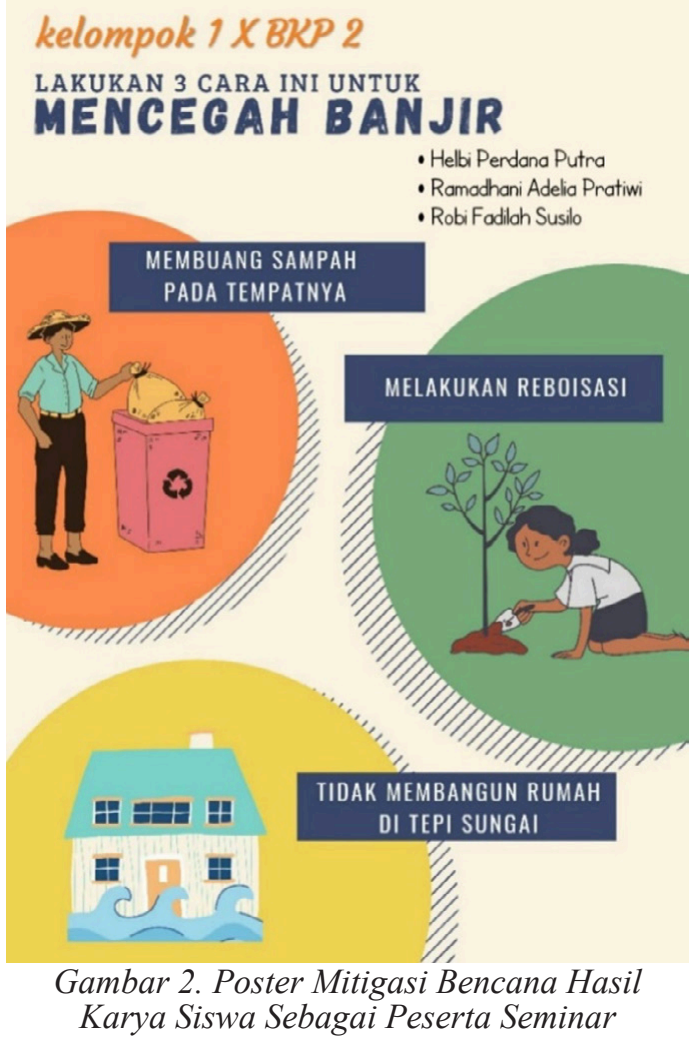

Tabel 1. Skor Pengetahuan Siswa

\begin{tabular}{clcc}
\hline No & \multicolumn{1}{c}{ Butir } & Pre-test & Post test \\
\hline 1 & $\begin{array}{l}\text { Berikan kritik terhadap perilaku masyarakat yang masih membuang sampah } \\
\text { sembarangan }\end{array}$ & 2.52 & 3.04 \\
\hline 2 & $\begin{array}{l}\text { Berikan tanggapan atas masyarakat yang masih menggunakan kantong plastik } \\
\text { untuk belanja }\end{array}$ & 2.96 & 3.50 \\
\hline 3 & $\begin{array}{l}\text { Berikan solusi atas permasalahan rendahnya daerah resapan air di lingkungan } \\
\text { sekitar mu }\end{array}$ & 2.76 & 2.98 \\
\hline 4 & $\begin{array}{l}\text { Solusi apa yang bisa dilakukan untuk merubah kebiasaan masyarakat untuk rajin } \\
\text { membersihkan saluran air }\end{array}$ & 3.09 & 3.70 \\
\hline 5 & Buatlah sebuah program inovatif yang mendukung upaya mitigasi banjir & 2.57 & 3.52 \\
\hline 6 & $\begin{array}{l}\text { ide inovatif apa yang bisa dikembangkan untuk mengkampanyekan mitigasi banjir } \\
\text { di media sosial }\end{array}$ & 3.17 & 4.22 \\
\hline & Rata-rata (Interval skor 0-100) & 28.45 & 34.93 \\
\hline & Kategori & Rendah & Rendah \\
\hline
\end{tabular}


Akan tetapi, siswa juga perlu meningkatkan pengetahuannya terlebih dahulu terkait dengan mitigasi banjir sebelum mengampanyekannya di media sosial dengan cara menambahkan kurikulum pembelajaran lingkungan, melakukan pengembangan bahan ajar, dan juga diadakan seminar-seminar terkait mitigasi banjir. Apabila kegiatan seminar ini rutin dilaksanakan, siswa pun akan matang dengan pengetahuan lingkungan. Kemudian, hal itu akan diimplementasikan pengetahuannya ke dalam lingkungan sekolah dan masyarakat. Jadi, siswa akan terbiasa menjaga lingkungan karena merasakan sendiri dampak-dampak apabila tidak melestarikan lingkungan.

Kegiatan seminar ini selain mengukur pengetahuan siswa mengenai mitigasi banjir, kegiatan tersebut juga mengukur perilaku siswa saat terjadi banjir dan setelah terjadi banjir. Cara mengukurnyaadalah dengan mengadakan pre-test dan post-test. Pre-test dilakukan sebelum pelaksanaan seminar dan untuk post-test dilaksanakan setelah selesai seminar. Kegiatan mengukur kemampuan ini bertujuan untuk melihat sejauh mana siswa memahami pengetahuan perilaku siswa sehingga siswa akan menerapkan perilaku mitigasi banjir tersebut. Perubahan perilaku ini menjadi penting dalam pembelajaran dan edukasi lingkungan hidup (Cheng \& Monroe, 2012; Jonell et al., 2016; Slavoljub et al., 2015).

Berdasarkan hasil dari pretest dan post-test, nilai yang didapat rata-rata menunjukan peningkatan. Hanya ada satu nilai yang mengalami penurunan, yaitu pada butir nomor empat dengan nilai penurunannya 0,05 . Dari hasil tersebut dapat diartikan bahwa secara umum siswa belum memiliki pemahaman yang maksimal walaupun sudah diadakan kegiatan seminar. Hal ini bisa terjadi karena dalam pembelajaran daring banyak faktor yang memengaruhi terhadap hasil ketercapaian.

Namun, di dalam hasil penilaian ini ada beberapa butir perilaku yang sudah dilakukan siswa dengan baik, seperti pada butir 2,5 dan 6 yang nilai pre-testnya sudah tinggi. Ini berarti siswa sudah memiliki pengetahuan tentang perilaku mitigasi banjir walaupun belum secara maksimal. Selain itu, ada satu butir yang nilai pre-test dan post-test masih kecil. Hal ini berarti masih rendahnya pengetahuan siswa mengenai perilaku mitigasi banjir, yaitu menyiapkan perahu karet/pelampung untuk proses evakuasi saat banjir datang.

$$
\text { Kegiatan pemberdayaan }
$$
keterampilan mitigasi bencana banjir

Tabel 2. Skor Perilaku Mitigasi Banjir

\begin{tabular}{llcc}
\hline No & \multicolumn{1}{c}{ Butir } & Pre-test & Post test \\
\hline 1 & Saya bergotong royong membersihkan saluran air & 2.93 & 3.33 \\
\hline 2 & Saya membuang sampah pada tempatnya & 4.74 & 4.87 \\
\hline 3 & Saya melakukan daur ulang sampah plastik secara rutin & 2.76 & 1.83 \\
\hline 4 & $\begin{array}{l}\text { saya menyiapkan perahu karet/pelampung untuk proses evakuasi saat banjir } \\
\text { datang }\end{array}$ & 4.93 \\
\hline 5 & saya meletakan barang elektronik di tempat yang aman agar tidak terendam banjir & 4.35 & 4.57 \\
\hline 6 & Saya menyimpan dokumen penting di tempat yang aman dari banjir & 2.24 & 4.74 \\
\hline 7 & saya mengkampanyekan pencegahan banjir di media sosial & 2.61 \\
\hline 8 & Saya membersihkan segera rumah setelah banjir surut & 4.80 \\
\hline 9 & $\begin{array}{l}\text { Saya menggunakan desinfektan anti bakteri untuk membersihkan rumah setelah } \\
\text { banjir }\end{array}$ & 3.39 \\
\hline 10 & Saya memetakan daerah rawan banjir sebelum berpergian & 3.61 \\
\hline & Rata-rata (Interval skor 0-100) & 2.70 \\
\hline & Kategori & 66.62 \\
\hline
\end{tabular}


dilaksanakan secara daring/online pada siswa SMK, yaitu pada siswa kelas $\mathrm{X}$ Kompetensi Keahlian Desain Pemodelan dan Informasi Bangunan dan Kompetensi Keahlian Bisnis Konstruksi dan Properti SMKN 1 Jakarta. Sekolah SMK mempunyai tujuan untuk menciptakan lulusan yang terampil dan kompeten di bidangnya, tetapi tidak mencantumkan pembelajaran mengenai mitigasi bencana. Dalam hal ini, siswa SMK mendapatkan pengetahuan tentang mitigasi banjir dan perilaku mitigasi hanya dari media, baik media cetak, elektronik, maupun media sosial. Kondisi ini sangatlah penting untuk memberikan suatu kegiatan kepada siswa SMK dalam menambah pengetahuan dan keterampilan siswa dalam berperilaku mitigasi bencana banjir. Namun, untuk melaksanakan kegiatan pendidikan mitigasi bencana kepada siswa SMK banyak kendala yang dihadapi sehingga kegiatan ini tidak mendapatkan hasil secara maksimal.

Rata-rata siswa SMK sangatlah sulit dikoordinasi untuk mengikuti kegiatan seminar apalagi jika tidak ada keterkaitan dengan pengetahuan yang berhubungan dengan kompetensi keahian mereka. Selain itu, siswa SMK mengangap bahwa mitigasi bencana merupakan pengetahuan umum yang sudah biasa mereka dapatkan dari media sehingga mereka merasa kurang tertarik. Berdasarkan hal ini perlu dilakukan implementasi siswa SMK untuk bisa menerapkan berbagai ilmu yang dimiliki untuk mencegah kejadian banjir. Untuk mengatasi kendala tersebut dalam kegiatan pendidikan mitigasi bencana, sangatlah penting menentukan media dan metode pembelajaran yang tepat untuk siswa (Lee, 2016; Saleh \& Filawati, 2019; Seechaliao, 2017).

Pemberdayaan masyarakat untuk mengatasi banjir menjadi penting untuk warga di perkotaan. Upaya untuk mengatasi masalah ini ternyata bisa dilakukan secara daring. Ke depannya, upaya pemecahan masalah banjir harus dilakukan dengan berbagai inovasi lain, misalnya, dengan melakukan upaya untuk mengatasi kekurangan edukasi terkait banjir, maka dibuat sebuah inovasi dalam media sosial warga masing-masing. Informasi dari berbagai sumber media sosial mereka diharapkan akan menjadikan berita baik bagi warga masyarakat lain untuk bisa lebih peduli terhadap masalah lingkungan yang ada di sekitar mereka.

Pengabdian masyarakat pada masa pendemi tetap perlu dilakukan. Sekalipun sulitnya akses bagi masyarakat untuk mendapatkan informasi secara langsung, media online masih dapat dimanfaatkan untuk menyampaikan informasi tersebut. Secara tidak langsung, media informasi yang bersifat online tersebut juga menjadi komponen penting bagi masyarakat untuk ke depannya. Pengabdian masyarakat yang inovatif seperti inilah yang perlu terus didorong untuk dilakukan secara berkala (Bahri et al., 2021; Marlina et al., 2021).

Hal terpenting yang harus dilakukan adalah mengimplementasikan apa yang sudah disampaikan saat seminar. Peserta kegiatan harus bisa mengaplikasikan berbagai konsep yang sudah diajarkan agar bisa bermanfaat untuk hidup seharihari. Masalah yang ada di lingkungan sekitarnya diharapkan bisa selesai apabila semua pihak bisa ikut serta menerapkan berbagai masalah yang ada di sekitar mereka. Ke depannya, upaya untuk melakukan perbaikan lingkungan perlu dilakukan sampai tingkat sekolah dasar.

Penerapan pendidikan lingkungan hidup di sekolah dasar masih relatif rendah. Hal itu disebabkan masih banyak siswa sekolah dasar yang belum memiliki pemahaman yang cukup terkait dengan mitigasi banjir. Oleh sebab itu, kita perlu mendorong untuk melakukan upaya penyuluhan dan edukasi lebih lanjut kepada siswa sekolah dasar, misalnya, dengan memberikan topik mitigasi bencana tersebut pada buku ajar. 
Pengembangan buku ajar tersebut menjadi penting untuk dilakukan karena dapat memberikan siswa informasi tambahan yang lebih banyak. Hasilnya adalah siswa akan bisa memberikan edukasi kepada sesama teman sebayanya. Hal ini akan memudahkan dalam upaya edukasi kita dalam mitigasi banjir. Siswa sekolah dasar bisa lebih mudah dalam bergaul dengan temannya. Dengan begitu, informasi penting terkait dengan mitigasi banjir bisa tersampaikan dengan cara yang lebih mudah untuk dipahami.

Sementara itu, edukasi yang lebih luas perlu diberikan kepada masyarakat. Tentunya, hal itu perlu mempertimbangkan berbagai faktor psikologis dari kelompok masyarakat tersebut. Salah satunya adalah kelompok pada jenjang pendidikan yang rendah hingga lulusan perguruan tinggi. Edukasi mengenai banjir ini harus diberikan kepada masyarakat luas dengan lebih saksama dan mengedepankan pendekatan pemahaman yang lebih baik. Pendidikan lingkungan hidup merupakan sebuah bentuk pendidikan yang mementingkan upaya untuk mengatasi masalah lingkungan (problem solver). Oleh karenanya, upaya untuk mengatasi lingkungan hidup tersebut menjadi lebih sesuai dan kontekstual dengan keadaan saat ini. Upaya itu menjadi penting untuk dilakukan secara lebih komprehensif.

Pendidikan mitigasi bencana diharapkan dapat diimplementasikan lebih lanjut pada berbagai kalangan. Harapannya secara langsung masyarakat dapat membuat berbagai upaya secara gotong royong untuk mengatasi bencana yang terjadi di kehidupan mereka secara lebih lanjut. Dalam hal ini, pendidikan lingkungan hidup yang dilakukan oleh berbagai kalangan perlu juga ditingkatkan. Lembaga dan organisasi pemerhati lingkungan harus lebih aktif dalam memberikan edukasi dan promosi tentang pentingnya menjaga lingkungan hidup. Hal ini terjadi karena lembaga lingkungan hidup juga merupakan komponen penting dari masyarakat yang memiliki peran dalam mengatasi masalah lingkungan hidup.

Sinergi antarlembaga tersebut dapat meningkatkan efektivitas dalam melaksanakan berbagai program lingkungan hidup sehingga lebih baik meningkatkan kemampuan masyarakat dalam pembelajaran lingkungan hidup. Upaya edukasi secara daring pun perlu dilakukan untuk terus melaksanakan pendidikan secara lebih berkelanjutan dan efisien.

\section{Kesimpulan dan Saran}

Berdasarkan hasil kegiatan seminar setelah diadakannya Pre-Test dan PostTest, didapatkan beberapa kesimpulan, yaitu kegiatan yang dilaksanakan berjalan dengan lancar dan terjadi interaksi yang baik antara narasumber dan peserta. Selain itu, peserta seminar membuat poster, komik, dan video sebagai upaya mengampanyekan mitigasi banjir di media sosial. Hasil skor terkait dengan pengetahuan dan perilaku siswa terhadap mitigasi banjir mengalami kenaikan setelah pelaksanaan seminar.

\section{DAFTAR PUSTAKA}

Al-Balushi, S. M., \& Al-Aamri, S. S. (2014). The effect of environmental science projects on students environmental knowledge and science attitudes. International Research in Geographical and Environmental Education, 23(3), 213-227. https://doi.org/10.1080/1 0382046.2014 .927167

Bahri, S., Simbolon, M., \& Rettob, A. L. (2021). Pelatihan Pembuatan Bahan Ajar Online Berbasis Web Pada Sekolah Menengah Kejuruan Negeri 1 Tanah Miring. Ethos: Jurnal Penelitian Dan Pengabdian Kepada Masyarakat, 9(2), 248259.

Buzov, I. (2014). Social network 
sites as area for students' proenvironmental activities. Procedia - Social and Behavioral Sciences, 152, 1233-1236. https://doi. org/10.1016/j.sbspro.2014.09.304

Cheng, J. C. H., \& Monroe, M. C. (2012). Connection to nature: Children's affective attitude toward nature. Environment and Behavior, 44(1), 31-49. https://doi. org/10.1177/0013916510385082

Gampell, A. V., Gaillard, J. C., Parsons, M., \& Fisher, K. (2017). Beyond stop disasters 2.0: An agenda for exploring the contribution of video games to learning about disasters. Environmental Hazards, 16(2), 180-191. https://doi.org/10.1080/1 7477891.2016 .1275502

Jonell, M., Crona, B., Brown, K., Rönnbäck, P., \& Troell, M. (2016). Eco-labeled seafood: determinants for (blue) green consumption. Sustainability, 8(9), 1-19. https:// doi.org/10.3390/su8090884

Kanchanabhandhu, C., \& Woraphong, S. (2016). A model of solid waste management based multilateral co-operation in semi-urban community. International Journal of Environmental and Science Education, 11(12), 5762-5775.

Knowlton, D. S., \& Sharp, D. C. (2015). Students' opinions of instructional strategies in a graduate-level creativity course. International Journal for the Scholarship of Teaching and Learning, 9(2), 1-12. http://digitalcommons. georgiasouthern.edu/ij-sotl/vol9/ iss $2 / 6$

Lee, A. Y. L. (2016). Media education in the school 2.0 era: Teaching media literacy through laptop computers and iPads. Global Media and China, 1(4), 435-449. https://doi. org/10.1177/2059436416667129

Marlina, E. T., Harlia, E., Hidayati, Y. A., \& Badruzzaman, D. Z. (2021). Penyuluhan Pengolahan Limbah
Ternak Dalam Upaya Mengurangi Emisi Gas Rumah Kaca. Ethos: Jurnal Penelitian Dan Pengabdian Kepada Masyarakat, 9(2), 307315.

Muthukrishnan, R., \& Kelley, J. E. (2017). Depictions of sustainability in children's books. Environment, Development and Sustainability, 19(3), 955-970. https://doi. org/10.1007/s10668-016-9778-7

$\mathrm{Ng}$, C. (2018). "I learn for a job promotion!": the role of outcomefocused career goals in motivating distance learners to learn. Distance Education, 39(3), 390-410. https:// doi.org/10.1080/01587919.2018.1 476839

Saleh, R., \& Filawati, F. (2019). Efektifitas penerapan model pembelajaran kooperatif tipe students team achievement division dalam meningkatkan aktivitas dan hasil belajar kognitif siswa. Edubiotik : Jurnal Pendidikan, Biologi Dan Terapan, 4(02), 75-82. https://doi. org/10.33503/ebio.v4i02.449

Seechaliao, T. (2017). Instructional strategies to support creativity and innovation in education. Journal of Education and Learning, 6(4), 201-208. https://doi.org/10.5539/ jel.v6n4p201

Slavoljub, J., Zivkovic, L., Sladjana, A., Dragica, G., \& Zorica, P. S. (2015). To the Environmental Responsibility among Students through Developing their Environmental Values. Procedia - Social and Behavioral Sciences, 171, 317-322. https://doi. org/10.1016/j.sbspro.2015.01.128

Sparrow, R., Dartanto, T., \& Hartwig, R. (2020). Indonesia Under the New Normal: Challenges and the Way Ahead. Bulletin of Indonesian Economic Studies, 56(3), 269-299. https://doi.org/10.1080/00074918. 2020.1854079

Talmi, I., Hazzan, O., \& Katz, R. (2018). 
76 | Rahmayanti, et al.

Intrinsic motivation and $21 \mathrm{st}-$ century skills in an undergraduate engineering project: the formula student project. Higher Education Studies, 8(4), 46. https://doi. org/10.5539/hes.v8n4p46

Xia, B. S. (2017). An In-Depth Analysis of Teaching Themes and the Quality of Teaching in Higher Education: Evidence from the Programming Education Environments. International Journal of Teaching and Learning in Higher Education, 29(2), 245-254.

Yusnaeni, Y., Corebima, A. D., Susilo, H., \& Zubaidah, S. (2017). Creative Thinking of Low Academic Student Undergoing Search Solve Create and Share Learning Integrated with Metacognitive Strategy. International Journal of Instruction, 10(2), 245-262. https://doi. org/10.1016/j.spinee.2011.10.010 